\title{
Seletividade de sulfentrazone na cultura do girassol
}

Estevam Matheus Costa ${ }^{1}$, Evelin Ventura Correa ${ }^{1}$, Jeovane Nascimento Silva ${ }^{2}$, Leandro Spíndola Pereira ${ }^{2}$, Leonardo Durval Duarte Guimarães ${ }^{3}$

${ }^{1}$ Universidade do Estado de Minas Gerais - UEMG, Programa de Pós Graduação em Ciências Agrárias, Unidade Ituiutaba. ${ }^{2}$ Instituto Federal Goiano- IF Goiano. ${ }^{3}$ Universidade Federal do Rio de Janeiro - UFRJ. E-mail: estevammcosta@yahoo.com.br

\section{Resumo}

Objetivou-se avaliar a seletividade da molécula sulfentrazone em pós emergência na cultura do girassol. O experimento foi conduzido no ano de 2014 em Campo Novo do Parecis. O delineamento foi em blocos casualizados com nove tratamentos e quatro repetições. Os tratamentos foram constituídos de sete doses de sulfentrazone $\left(50,62,5,75,87,5,100,112,5\right.$ e $125 \mathrm{~g}$ i.a ha ${ }^{-1}$ ) e uma testemunha com capina manual. A aplicação do herbicida foi realizada com pulverizador costal pressurizado a $\mathrm{CO}_{2}$ e equipado com barra de aplicação contendo cinco pontas do modelo TeeJet XR 11002 VS, com volume de aplicação de $200 \mathrm{~L} \mathrm{ha}^{-1}$. Foi avaliada a fitotoxicidade (\%), altura do capítulo, diâmetro da haste, massa do capítulo, massa de aquênios por capítulo, produtividade e massa de mil aquênios. Houve redução na altura do capítulo nas doses de 112,5 e $125 \mathrm{~g}$ i.a ha ${ }^{-1}$, enquanto que nas demais variáveis não foram observadas diferenças significativas. Até os 14 dias após a aplicação (DAA) foram observadas algumas injúrias. A produtividade não foi afetada pelas doses de sulfentrazone. Que se mostraram seletivas à cultura do girassol.

Palavras-chave: fitotoxicidade; Helianthus annuus; herbicida; inibidores da Protox; seletividade.

\section{Selectivity of sulfentrazone in sunflower crop}

\begin{abstract}
The objective of this study was to evaluate the selectivity of the post emergent sulfentrazone molecule in sunflower crop. The experiment was conducted in 2014 in Campo Novo do Parecis. The design was in randomized blocks with nine treatments and four replications. Treatments consisted of seven doses of sulfentrazone $\left(50,62.5,75,87.5,100,112.5\right.$ and $125 \mathrm{~g}$ i.a ha $\left.{ }^{-1}\right)$ and a control with weeding. The herbicide application was carried out with a $\mathrm{CO}_{2}$ pressurized costal sprayer and equipped with an application bar containing five TeeJet XR 11002 VS tips, with an application volume of $200 \mathrm{~L} \mathrm{ha}^{-1}$. Phytotoxicity (\%), chapter height, stem diameter, chapter mass, achenes mass per chapter, yield and thousand achenes mass were evaluated. There was a reduction in chapter height at 112.5 and $125 \mathrm{~g}$ i.a ha ${ }^{-1}$, while no significant differences were observed in the other variables. Up to 14 days after application (DAA) some injuries were observed. Yield was not affected by sulfentrazone doses. Which proved selective to sunflower crop.

Keywords: phytotoxicity; Helianthus annuus; herbicide; protox inhibitors; selectivity.
\end{abstract}

\section{Introdução}

O girassol (Helianthus annuus) possui diversas utilidades para a alimentação humana e animal, que incentiva a produção no cerrado brasileiro (DAN et al., 2012). Na safra 2018/2019 a produção brasileira de girassol foi de 104,9 mil toneladas. A área ocupada por girassol no brasil é de $62,8 \mathrm{mil}$ ha, distribuídos nas regiões centrooeste, sudeste e sul (CONAB, 2018). 
O controle químico de plantas daninhas na cultura do girassol é uma das mais tecnologias de maior relevância, visto que esta cultura apresenta crescimento inicial lento e baixa cobertura do solo, o que favorece o crescimento das plantas daninhas nas áreas de cultivo (MASCARENHA et al., 2004). Em função do crescimento inicial lento, até os 40 dias após a emergência, que representa o período total de interferência a cultura do girassol, é uma espécie bastante suscetível à presença de plantas daninhas (MASCARENHAS et al., 2012).

A presença de 15-40 plantas de Bidens pilosa durante o período crítico de interferência na cultura do girassol causa perdas diárias de 1,1 $\mathrm{kg} \mathrm{ha}^{-1}$ no rendimento de óleo e de $2,5 \mathrm{~kg} \mathrm{ha}^{-1} \mathrm{na}$ produtividade, enquanto que na ausência de plantas daninhas, até os 30 dias após a emergência, o ganho diário é de $6,5 \mathrm{~kg} \mathrm{ha}^{-1}$ no rendimento de óleo e de $14,4 \mathrm{~kg} \mathrm{ha}^{-1}$ na produtividade (BRIGHENTI et al., 2004). O controle eficiente de plantas daninhas deve incluir medidas de manejo integrado, e dentre elas, o uso de herbicidas seletivos à cultura (MASCARENHAS et al., 2012).

A seletividade de um herbicida é determinada pela capacidade de um determinado eliminar as plantas daninhas que se encontram em uma cultura sem reduzir-lhe a produtividade, com a presença ou não de sintomas visuais, caracterizados por injúrias foliares (VELINI et al., 2000). As informações referentes à seletividade de herbicidas na cultura do girassol são limitadas (Mascarenhas et al., 2012). A principal limitação de uso de herbicidas nesta cultura está na falta de opções de produtos registrados, sobretudo para controle de espécies dicotiledôneas, entretanto existem diversos produtos com efeito sobre gramíneas já registrados no Brasil (SILVA et al., 2012).

A sulfentrazone é um herbicida inibidor da Protox (protoporfirinogênio oxidase), registrado para aplicação em pré ou pósemergência das plantas daninhas na cultura da soja e cana-de-açúcar para o controle de folhas largas e gramíneas. Pertence ao grupo das Ariltriazolinonas (TOMLIN, 1994; BLANCO; VELINI, 2005), e seu modo de ação caracteriza-se como destruidor de membranas celulares, inibindo a enzima Protox, ocasionando o acúmulo de Protoporfirinogênio, formação de $\mathrm{O}_{2}$, que leva à peroxidação de lipídeos e consequentemente à destruição das membranas celulares ( BLANCO; VELINI, 2005).
Objetivou-se avaliar a seletividade de doses entre 50 e $125 \mathrm{~g}$ de sulfentrazone $\mathrm{ha}^{-1}$, aplicado em pós-emergência da cultura do girassol.

\section{Material e Métodos}

A pesquisa foi realizada no município de Campo Novo do Parecis-MT, no ano agrícola de 2014, na área experimental do Instituto Federal de Educação, Ciência e Tecnologia de Mato Grosso - Campus Campo Novo do Parecis. O solo foi classificado como Latossolo Vermelho Distrófico típico, com relevo levemente ondulado e boa porosidade (EMBRAPA, 2013).

A área está situada a uma altitude de 564 metros, e as coordenadas geográficas são: $13^{\circ} 40^{\prime} 37^{\prime \prime}$ S e $57^{\circ} 47^{\prime} 30^{\prime \prime}$ O. O clima da região é caracterizado como Aw, ou seja, clima tropical com temperaturas elevadas, maiores precipitações no verão e períodos de seca no inverno, conforme classificado por Köppen, (VIANELLO; ALVES, 2004). Durante a execução do experimento, as condições climáticas foram de $30,3^{\circ} \mathrm{C} ; 23,2^{\circ} \mathrm{C}$ e $18,9^{\circ} \mathrm{C}$ para a temperatura máxima, média e mínima, respectivamente, e precipitação acumulada de $570 \mathrm{~mm}$.

O delineamento foi em blocos casualizados com nove tratamentos e quatro repetições. Os tratamentos foram constituídos por sete doses de sulfentrazone $(50,62,5,75$, $87,5,100,112,5$ e 125 g i.a ha ${ }^{-1}$ ) e uma testemunha capinada. A área total de cada parcela foi de $13,5 \mathrm{~m}^{2}(2,7 \times 5 \mathrm{~m})$, sendo considerada como área útil apenas $3,6 \mathrm{~m}^{2}$ centrais.

O controle de plantas daninhas em présemeadura foi realizado com a aplicação de 1,75 $\mathrm{kg}$ do i.a ha ${ }^{-1}$ de glyphosate, dois dias antes da semeadura do girassol. A cultivar semeada foi a Charrua de forma manual, a $5 \mathrm{~cm}$ de profundidade, com densidade de 2,25 plantas por metro linear. Com 15 dias após emergência (DAE), foi realizado o desbaste de plantas visando a obtenção de uma população de 50.000 plantas ha ${ }^{-1}$. A adubação de base foi $200 \mathrm{~kg} \mathrm{ha}^{-1}$ de NPK na formulação 8-20-20. A adubação de cobertura foi realizada aos 19 (DAE) com a aplicação de $45,59 \mathrm{~kg} \mathrm{ha}^{-1}$ de $\mathrm{N}$ e $13,5 \mathrm{~kg} \mathrm{ha}^{-1}$ de $\mathrm{K}_{2} \mathrm{O}$. Aos 22 (DAE) realizou-se adubação com fonte de Boro a $1,6 \mathrm{~kg} \mathrm{ha}^{-1}$.

As sementes foram tratadas próximo do momento de semeadura. E durante o ciclo da cultura foram realizadas três aplicações de inseticidas e uma aplicação para doenças de final 
de ciclo. Aos 19 DAE foi realizada uma capina manual no tratamento que não recebeu aplicação do herbicida.

As doses do herbicida sulfentrazone foram aplicadas no estádio $V_{4}$ (quatro folhas totalmente desenvolvidas) com auxílio de um pulverizador costal pressurizado a $\mathrm{CO}_{2}$ equipado com barra de aplicação contendo cinco bicos de pulverização da marca TeeJet, e modelo XR 110 02 VS. O volume de calda foi de $200 \mathrm{~L} \mathrm{ha}^{-1}$, que foram aspergidos quando a velocidade do vento encontrava-se à $3 \mathrm{~m} \mathrm{~s}^{-1}$, e umidade relativa de $60 \%$.

A colheita do girassol foi realizada de forma manual aos 103 (DAE). As variáveis avaliadas foram: fitotoxicidade, altura do capítulo (AC), diâmetro da haste (DH), massa do capítulo (MC), massa de aquênios por capítulo (MC), massa da parcela (MP), massa de mil aquênios (MMA) e produtividade (P).

A avaliação da fitotoxicidade nas plantas foi realizada de maneira visual aos 2, 7, 14, 21 e 28 dias após a aplicação do herbicida (DAP) atribuindo notas em escala de zero a cem, e atribuição de notas que variam de 0 a $100 \%$, onde 0 representa nenhuma injúria e $100 \%$ representa morte das plantas (SBCPD, 1995).

Os resultados foram submetidos à análise de variância e as médias dos resultados significativos das variáveis foram comparadas pelo teste de Dunnett a $5 \%$ de probabilidade e análise de regressão quando constatadas diferenças significativas.

\section{Resultados e Discussão}

De acordo com a análise de variância para as variáveis Diâmetro da Haste, Massa do Capítulo, Massa de Aquênios por Capítulo, Massa da Parcela e Massa de Mil aquênios não houve diferença significativa em função das doses utilizadas, somente a altura do capítulo afetada pelos tratamentos (Tabela 1).

A altura do capítulo nas doses 112,5 e $125 \mathrm{~g}$ i.a ha ${ }^{-1}$ não apresentaram diferença significativa em relação à testemunha capinada. Entretanto, altura do capítulo foi reduzida de acordo com o incremento das doses de sulfentrazone. Ao se comparar o tratamento referente a $125 \mathrm{~g}$ i.a ha ${ }^{-1}$ de sulfentrazone com a testemunha, observa-se redução de 6,5 \% (Tabela 1). Foi possível ajustar um modelo quadrático para a variável altura do capítulo, com coeficiente de determinação $\left(R^{2}\right)$ de $92 \%$, com redução em função do aumento das doses do herbicida (Figura 1). Enquanto que, Queiroz (2016) não observou redução da altura das plantas de girassol em função da aplicação de sulfentrazone na dose de $400 \mathrm{~g}$ i.a ha ${ }^{-1}$.

Tabela 1. Altura do capítulo ( $A C)$, diâmetro da haste (DH), massa do capítulo (MC), massa de aquênios por capítulo (MA), massa de mil aquênios (MMA) e produtividade $(P)$ da cultura do girassol submetidas a diferentes doses de sulfentrazone em pós emergência, Campo Novo do Parecis-MT, 2014

\begin{tabular}{|c|c|c|c|c|c|c|}
\hline $\begin{array}{l}\text { Dose } \\
\left(\mathrm{mL} \mathrm{ha}{ }^{-1}\right)\end{array}$ & $\begin{array}{l}\text { AC } \\
\text { (m) }\end{array}$ & $\begin{array}{l}\text { DH } \\
(\mathrm{mm})\end{array}$ & $\begin{array}{l}\text { MC } \\
\text { (g) }\end{array}$ & $\begin{array}{l}\text { MA } \\
\text { (g) }\end{array}$ & $\begin{array}{l}\text { MMA } \\
\text { (g) }\end{array}$ & $\begin{array}{l}\text { P } \\
\left(\mathrm{kg} \mathrm{ha}^{-1}\right)\end{array}$ \\
\hline $0^{\text {C.C. }}$ & $1,75 \mathrm{a}$ & 19,45 & 395,2 & 7 & 37,23 & 1526 \\
\hline 100 & $1,79 a b$ & $18,1^{\mathrm{ns}}$ & $366,7^{\text {ns }}$ & $22229,2^{\mathrm{ns}}$ & $38,5^{\mathrm{ns}}$ & $1559^{\mathrm{ns}}$ \\
\hline 125 & $1,78 a b$ & 18,8 & 336,7 & 197,2 & 39,2 & 1423 \\
\hline 150 & $1,78 a b$ & 19,2 & 407,0 & 226,2 & 40,2 & 1338 \\
\hline 175 & $1,76 a b$ & 18,8 & 375,2 & 208,7 & 39,7 & 1342 \\
\hline 200 & $1,73 a b$ & 19,8 & 346,0 & 195,2 & 41,9 & 1526 \\
\hline 225 & $1,69 \mathrm{~b}$ & 20,3 & 381,5 & 235,0 & 40,1 & 1472 \\
\hline 250 & $1,70 \mathrm{~b}$ & 19,5 & 403,2 & 232,5 & 42,1 & 1599 \\
\hline CV (\%) & 2,91 & 6,59 & 16,44 & 15,60 & 10,16 & 15,60 \\
\hline
\end{tabular}

Médias seguidas por letras distintas nas colunas diferem-se entre si pelo teste de Dunnett $(p<0,05)$ 
Figura 1. Altura do capítulo em função das diferentes doses de sulfentrazone na cultura do girassol, Campo Novo do Parecis-MT, 2014

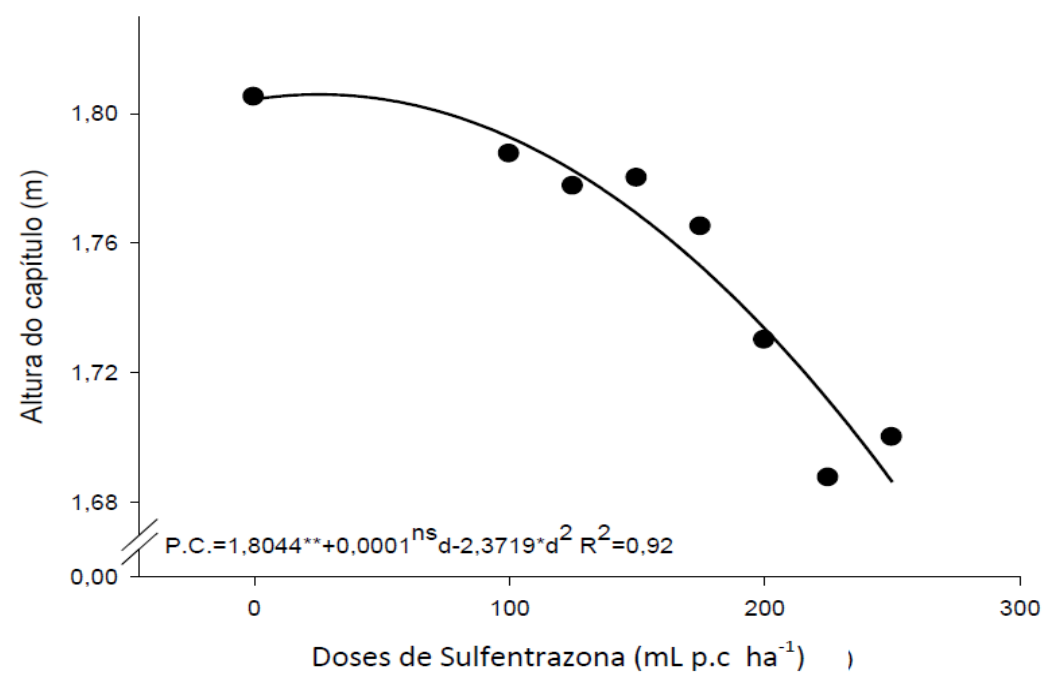

O diâmetro da haste, a massa do capítulo, massa de aquênios po $r$ capítulo e a massa de mil aquênios não foram afetados pelas doses de sulfentrazone. Nos trabalhos realizados por Nooryazdan et al. (2010), Pivetta et al. (2012) e Rigon et al. (2013) ficou evidente a correlação positiva entre diâmetro de capítulo e a produtividade. Desta forma, pode-se afirmar que as doses do herbicida não afetaram a produtividade (Tabela 1). Queiroz (2016) observou diferenças na produtividade de plantas de girassol tratadas em pré-emergência com moléculas de flumioxazin $\left(50 \mathrm{~g} \mathrm{ha}^{-1}\right)$, metribuzin (480 $\mathrm{g} \mathrm{ha}^{-1}$ ), oxyfluorfen $\left(480 \mathrm{~g} \mathrm{ha}^{-1}\right)$, smetolachlor (960 $\mathrm{g} \mathrm{ha}^{-1}$ ) e sulfentrazone (400 g $\mathrm{ha}^{-1}$ ), sendo que as plantas de girassol apresenta menor seletividade ao metribuzin e apresentaram maior produtividade em relação aos demais tratamentos. Enquanto, que as plantas de girassol apresentam maior seletividade ao sulfentrazone, que possui menor efeito residual, que favorece o surgimento de plantas daninhas, consequentemente a redução de produtividade.

A fitotoxicidade observada nas plantas de girassol aos dois dias após aplicação (DAA) aumentou de acordo com a dose de sulfentrazone. Os tratamentos envolvendo as doses de $87,5,100,112,5$ e $125 \mathrm{~g}$ de sulfentrazone $\mathrm{ha}^{-1}$, promoveram injúrias de até $45 \%$ (Figura 2). A absorção de sulfentrazone ocorre em maior parte pelo sistema radicular e apresenta baixa translocação via pelo floema, sendo um dos fatores que justifica sua baixa fitotoxicidade em pós-emergência. O principal sintoma de fitotoxidez de sulfentrazone é a necrose foliar que ocorre de 4 a 6 horas após aplicação e sob luz solar (BELO et al., 2011). 
Figura 2. Fitotoxicidade após aplicação de diferentes doses de sulfentrazone ( $\mathrm{mL} \mathrm{p.c} \mathrm{ha}{ }^{-1}$ ) na cultura do Girassol, Campo Novo do Parecis-MT, 2014

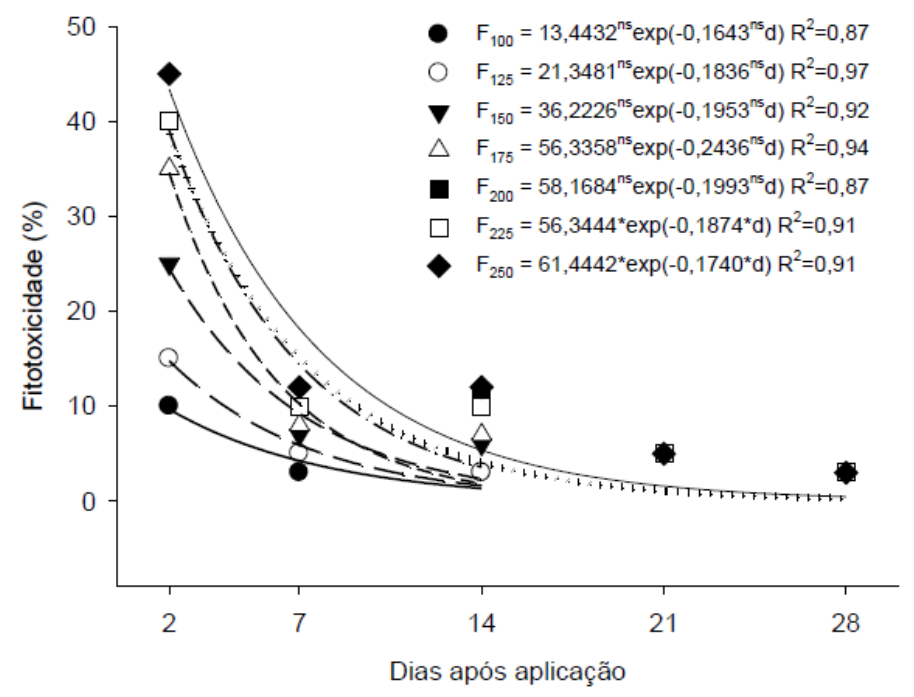

$\mathrm{Na}$ avaliação realizada aos 7 DAA, houve redução na porcentagem de fitotoxidez em todos os tratamentos, estando os valores de injúria abaixo de $15 \%$. Na terceira avaliação, realizada aos 14 DAA, os valores de fitotoxidez nas plantas se mantiveram estáveis em relação à segunda avaliação (Figura 2).

Nas avaliações realizadas aos 21 e 28 DAA não foram observadas injúrias nos tratamentos com doses de $50,62,5,75,87,5$ e $100 \mathrm{~g}_{\text {i.a }} \mathrm{ha}^{-1}$. Nas doses de 112,5 e 125 g i.a ha ${ }^{-1}$ as plantas apresentaram valores mais próximos de fitotoxidez, sendo estes de até $5 \%$, evidenciando tolerância moderada em tratamentos com doses acima de $112,5 \mathrm{~g}$ i.a ha ${ }^{-1}$ (Figura 2). Queiroz (2016) observou injúrias aos 30 DAA de 5,1, 5,0 e de $1,5 \%$ nas aplicações de $400 \mathrm{~g}$ i.a ha ${ }^{-1}$ em três diferentes cultivares de girassol quando a molécula foi pulverizada em pré-emergência.

A aplicação de sulfentrazone em préemergência na dose de $400 \mathrm{~mL}$ p.c ha ${ }^{-1}$ provocou injúrias no girassol dos 15 aos 45 dias após a semeadura (DAS) (SANTOS et al., 2012). Dan et al. (2012) estudando "carryover" de sulfentrazone no girassol, quando a cultura foi semeada aos 115 dias após a aplicação (DAA) dos herbicidas de pré-emergência, e aos 97 DAA dos herbicidas de pós-emergência, observou fitotoxidez de 9,2 e $1,5 \%$ de fitotoxidez aos 7 e 28 dias após a emergência do girassol, quando o girassol os herbicidas foram aplicados 115 dias. (BRIGHENTI et al., 2015a). Reis et al. (2014) observaram 7,5\% de fitotoxidez aos 50 DAA de sulfentrazone aplicada em pré-emergência na dose de $500 \mathrm{~g}$ i.a $\mathrm{ha}^{-1}$.
A produtividade não foi afetada pelas doses de sulfentrazone, demonstrando que doses de até $250 \mathrm{ml} \mathrm{ha}^{-1}$ de sulfentrazone aplicada em $\mathrm{V}_{4}$ não reduz a produtividade da cultura do girassol, mesmo sendo observadas injúrias até os 14 DAA, desta forma, em função da recuperação das injúrias nas plantas, após os 14 DAA. A produtividade foi $6 \%$ menor no tratamento que não recebeu aplicação de sulfentrazone. A convivência entre a cultura e a comunidade infestante permitiu intensa interferência competitiva resultando em $76,83 \%$ de redução na produtividade influenciada pela presença de plantas daninhas (ALVES et al., 2013).

As perdas na produtividade do girassol devido às plantas daninhas são mais evidentes na fase inicial da cultura (QUEIROZ, 2016). Cada dia de convivência do girassol com plantas daninhas ocasiona redução de $2,5 \mathrm{~kg} \mathrm{ha}^{-1}$ na produtividade (BRIGHENTI et al., 2004). As doses de sulfentrazone entre 114,2 e 158,8 g i.a ha ${ }^{-1}$ apresentaram controle satisfatório de plantas voluntárias de soja, evitando a competição com essa cultura (BRIGHENTI et al., 2015b).

Em plantas de soja tolerantes ao herbicida sulfentrazone ocorre rápida degradação oxidativa do produto como forma de destoxificação pela enzima peroxidase (OSIPE et al., 2008). Contudo, o girassol também é uma planta dicotiledônea (TOMICH et al., 2003), que pode ter favorecido para que as plantas podem ter se desintoxicado da mesma forma que ocorre com as plantas de soja.

O girassol apresentou tolerância ao sulfentrazone, visto que o herbicida não afetou o 
crescimento da cultura. Belo et al. (2011) relataram a seletividade do herbicida sulfentrazone para a cultura do girassol em doses variando de 250 a $500 \mathrm{~g}$ i.a ha ${ }^{-1}$. O principal fator para a tolerância de algumas plantas ao sulfentrazone é devido o metabolismo diferencial do herbicida, embora outros efeitos, como o movimento limitado desse produto a partir do local de aplicação até o sítio de ação, tenham sido observados (REIS et al., 2014).

\section{Conclusão}

As doses de sulfentrazone foram seletivas para a cultura do girassol, havendo redução apenas na altura do capítulo. As plantas se recuperaram das injúrias provocadas pelo herbicida entre 14 e 21 DAA, não comprometendo a produtividade da cultura.

\section{Referências}

ALVES, G.S. et al. Períodos de interferência das plantas daninhas na cultura do girassol em Rondônia. Revista Brasileira de Engenharia Agrícola e Ambiental, v.17, n.3, p.275-283, 2013. https://doi.org/10.1590/S1415-

\section{5}

BELO, A. F.; COELHO, A. T. C. P.; FERREIRA, L. R.; SILVA, A. A.; SANTOS, J.B. Potencial de espécies vegetais na remediação de solo contaminado com sulfentrazone. Planta Daninha, v.29, p.821828, 2011. https://doi.org/10.1590/S0100$\underline{83582011000400012}$

BLANCO, F. M. G.; VELINI, E. D. Persistência do herbicida sulfentrazone em solo cultivado com soja e seu efeito em culturas sucedâneas. Planta Daninha, v.23, n.4, p.693-700, 2005. https://doi.org/10.1590/S0100$\underline{83582005000400018}$

BRIGHENTI, A. M. et al. Inibição temporária do crescimento de plantas voluntárias de soja na cultura do girassol. In: REUNIÃO NACIONAL DE PESQUISA DE GIRASSOL, 21.; SIMPÓSIO NACIONAL SOBRE A CULTURA DO GIRASSOL, 9., 2015, Londrina. Anais [...]. Londrina: Embrapa Soja, 2015a. https://doi.org/10.1590/S0100$\underline{83582004000200012}$

BRIGHENTI, A. M. et al. Períodos de interferência de plantas daninhas na cultura do girassol. Planta daninha, v. 22, n. 2, p. 251-257, 2004.
BRIGHENTI, A. M. et al. Supressão do crescimento de plantas voluntárias de soja na cultura do girassol. In: REUNIÃO NACIONAL DE PESQUISA DE GIRASSOL, 21.; SIMPÓSIO NACIONAL SOBRE A CULTURA DO GIRASSOL, 9., 2015, Londrina. Anais [...]. Londrina: Embrapa Soja, 2015b.

CASTRO, C.; CASTIGLIONI, V.B.R.; BALLA, A.; LEITE, R.M.V.B.C.; KARAM, D.; MELLO, H. C.; GUEDES, L. C. A.; FARIAS, J. R. B. A cultura do girassol. Circular técnica, v.3, p.09-27, 1996.

CONAB. Acompanhamento da safra brasileira: grãos. Décimo segundo levantamento, setembro 2019. v. 6, n. 12, 2019.

DAN, H. A. et al. Atividade residual de herbicidas usados na soja sobre o girassol cultivado em sucessão. Ciência Rural, v.42, n.11, p.1929-1935, $2012 . \quad$ https://doi.org/10.1590/S0103$\underline{84782012005000081}$

EMBRAPA. Sistema Brasileiro de Classificação de Solos. 3. ed. rasília: Centro Nacional de Pesquisa de Solos, 2013.

MASCARENHAS, M. H. T.; KARAM, D.; LARA, J. F. $R$. Seletividade de herbicidas e dinâmica populacional de plantas daninhas na cultura do girassol para a produção de biodiesel. Revista Brasileira de Herbicidas, v. 11, n. 2, p. 174-186, 2012. https://doi.org/10.7824/rbh.v11i2.155

NOORYAZDAN, H. et al. Construction of a cropwild hybrid population for broadening genetic diversity in cultivated sunflower and first evaluation of its combining ability: the concept of neodomestication. Euphytica, v. 178, n.2, p.159175, 2011. https://doi.org/10.1007/s10681-010$\underline{0281-1}$

OSIPE, J. B. et al. Associação de sulfentrazone e glyphosate para o controle de plantas daninhas na cultura da soja $\mathrm{RR}^{\circledR}$. Revista Brasileira de Herbicidas, v.7, n.1, p.15-25, 2008. https://doi.org/10.7824/rbh.v7i1.49

PIVETTA, L. G. et al. Evaluation of sunflower hybrids and the relationship between productive and qualitative parameters. Revista Ciência Agronômica, v.43, n.3, p.561-568, 2012. https://doi.org/10.1590/S1806$\underline{66902012000300020}$ 
QUEIROZ, G.P. Eficácia de herbicidas em préemergência na cultura do girassol. 2016. 22 f. Dissertação (Mestrado) - Curso de Programa de Pós-graduação em Fitotecnia, Universidade Federal de Viçosa, Viçosa, 2016.

REIS, R.M. et al. Aspectos fisiológicos e crescimento do girassol após aplicação de herbicidas em pré-emergência. Revista Agro@mbiente On-line, v.8, n.3, p.352-358, 2014. https://doi.org/10.5327/Z1982$\underline{8470201400032171}$

RIGON, C.A.G.; RIGON, J.P.G.; CAPUANI, S. Parâmetros genéticos entre caracteres quantitativos no girassol como critério de seleção para produtividade de aquênios. Bioscience Journal, p. 1120-1125, 2013.

SANTOS, G. et al. Uso do novo sistema Clearfield na cultura do girassol para o controle de plantas daninhas dicotiledôneas. Planta Daninha, v.30, n.2, p.359-365, 2012. https://doi.org/10.1590/S0100$\underline{83582012000200015}$

SILVA, J.I.C. et al. Determinação dos períodos de interferência de plantas daninhas na cultura do girassol. Planta Daninha, v.30, n.1, p.27-36, 2012. https://doi.org/10.1590/S0100-

$\underline{83582012000100004}$

SBCPD. Procedimentos para instalação, avaliação e análise de experimentos com herbicidas. Londrina: SBCPD, 1995. $42 \mathrm{p}$.

TOMICH, T. R.; RODRIGUES, J. A. S.; GONÇALVES, L. C.; TOMICH, R. G. P.; CARVALHO, A. U. Potencial forrageiro de cultivares de girassol produzidos na safrinha para ensilagem. Arquivo Brasileiro de Medicina Veterinária e Zootecnia, v.55, p.756-762, 2003. https://doi.org/10.1590/S0102-

$\underline{09352003000600013}$

VELINI, E.D.; MARTINS, D.; MANOEL, L. A.; MATSUOKA, S.; TRAVAIN, J. C.; CARVALHO, J. C. Avaliação da seletividade da mistura de oxyfluorfen e ametryne, aplicada em pré ou pósemergência, a dez variedades de cana-de-açúcar (cana-planta). Planta Daninha, v.18, p.123-134, 2000. https://doi.org/10.1590/S0100-
VIANELLO, R.L.; ALVES, A.R. Meteorologia básica e aplicações. Viçosa: UFV, 2004. 449p. 